\title{
DESENVOLVENDO JOGOS EDUCACIONAIS POR MEIO DE SOFTWARES DE AUTORIA
}

\author{
Roseli Bertin, UCS, bertin_cx93@hotmail.com \\ Maria de Fátima Webber do Prado Lima, CCET/UCS, mfwplima@ucs.br \\ Carine Geltrudes Webber, CCET/UCS, cgwebber@ucs.br
}

\begin{abstract}
Resumo. Softwares de autoria são ferramentas para desenvolvimento de aplicações multimídia. Elas veem sendo empregadas com sucesso no desenvolvimento de softwares educacionais por serem ferramentas que não exigem conhecimentos sofisticados em programação. Contudo a área carece de um estudo avaliativo que permita atestar quais softwares de autoria são mais apropriados para a criação de jogos educacionais. Primeiramente este artigo aborda elementos presentes em jogos que possam ser aplicados em projetos educacionais. A partir de um conjunto de critérios este artigo propõe uma análise de softwares de autoria. Os softwares foram testados e avaliados pelo método analítico hierárquico. Como resultado o software de autoria melhor avaliado foi o Visual Class.
\end{abstract}

Palavras chaves: Jogos educacionais, Softwares de autoria.

\section{IMPLEMENTING EDUCATIONAL GAMES THROUGH AUTHORING TOOLS}

\begin{abstract}
Authoring tools are a kind of generic software for developing multimedia applications. They have been successfully employed in the development of educational software since they do not demand sophisticated programming knowledge. However the area lacks of a rating study to attest which authoring tool is the most appropriated to create educational games. First this article approaches game elements that can be applied in educational projects. From a set of important criteria, this article proposes an analysis over free authoring tools. They were tested and evaluated through analytical hierarchical method. As a result, the best evaluated authoring tool was Visual Class.
\end{abstract}

Keywords: Educational Games, Authoring tools.

\section{Introdução}

Atualmente os jogos digitais são formas de entretenimento bastante populares. A popularização dos jogos ocorreu graças as suas características intrínsecas de divertir, motivar, engajar o usuário em resolver problemas e aprender (FARDO, 2013). Denomina-se gamificação o processo de introduzir os elementos naturalmente encontrados em jogos digitais (mecanismos, dinâmicas e estética) em aplicações com fins educacionais, empresariais ou outros (NAVARRO, 2013; POSSANI, SANTOS e LOPES, 2013; AVELLAR et al., 2012). Em particular a área da educação vêm se apropriando rapidamente desse conceito de forma a suprir suas demandas. Estudos indicam que a gamificação pode alcançar todo o seu potencial na área da educação 
através da integração entre elementos de jogos e métodos didáticos (QUADROS, 2013).

Contudo, o desenvolvimento de tecnologias educacionais gamificadas constitui um desafio interdisciplinar que envolve estudos aprofundados em Didática, em Jogos e em Engenharia de Software. Estes três eixos precisam se inter-relacionar de forma apropriada para que resultados benéficos em termos de aprendizagem sejam produzidos. Neste cenário, o presente artigo propõe uma análise sobre os eixos jogos e software com o objetivo de avaliar a adequação de softwares de autoria em projetos de desenvolvimento de jogos educacionais. Os softwares de autoria são utilizados para desenvolver aplicações multimídias em diversas áreas. $\mathrm{Na}$ educação, os sistemas de autoria permitem que o professor e os alunos criem, implementem e testem aplicações (FALKEMBACH, 2007). Uma das vantagens no uso desses sistemas está na rapidez com que aplicações simples podem ser implementadas, já que elas utilizam linguagem de programação de alto nível (orientadas a eventos).

Os softwares de autoria podem constituir ferramentas úteis para que professores de diversas disciplinas construam seus próprios jogos educacionais. Para tratar desse assunto, o artigo proposto está organizado em 6 seções. Inicialmente a seção 2 apresenta os principais elementos encontrados em jogos eletrônicos relevantes para projetos educacionais. Na seção 3 são analisados quatro jogos populares onde tais elementos foram identificados. A partir deles foram elaborados critérios para avaliação dos softwares de autoria (seção 4). A seção 5 aborda o Método Analítico Hierárquico (MAH) utilizado para comparação dos softwares de autoria. Por fim, a seção 6 conclui o estudo realizado e aponta resultados preliminares.

\section{Jogos Digitais na Educação}

Prensky (2002) sustenta que um dos grandes problemas da aprendizagem é manter os alunos motivados, pois toda aprendizagem exige esforço e os alunos raramente querem fazê-lo sem um motivo. A aprendizagem deve ocorrer graças a uma combinação de elementos, objetivos intrínsecos, recompensas extrínsecas e fatores psicológicos. Cabe ao professor explorar esses fatores para estimular a vontade de aprender.

Segundo autores como Domínguez et al. (2013) e Alvez et al. (2012) ainda são necessários estudos e testes para reconhecer e validar os elementos presentes nos jogos que possam ser benéficos para a educação. De acordo com McGonigal (2012), muitos jogos possuem em comum características que contribuem para o envolvimento do jogador, tais como: o objetivo a ser alcançado; as regras que indicam limites e restrições para se alcançar o objetivo; um sistema de feedback que sinaliza ao jogador a proximidade de atingir o objetivo; e a participação voluntária onde há a aceitação consciente e voluntária do jogador em relação aos objetivos, regras e feedback do jogo.

Segundo Gee (2005) os jogos digitais, além de trabalharem com conteúdos, utilizam domínios semióticos para promover a aprendizagem. O autor lista os seguintes princípios de aprendizagem presentes nos jogos: identidade; interação, produção, riscos, customização, ação, boa ordenação dos problemas, desafio e fusão, atuação por demanda, significados contextualizados, frustração prazerosa, pensamento sistemático, revisão dos objetivos, equipes multifuncionais e desempenho antes da competência.

Para Kapp (2012) alguns elementos adicionais presentes nos jogos contribuem potencialmente para o engajamento do jogador: apresentar um conflito, estimular a competição e/ou a cooperação, oferecer uma forma de recompensa com pontos ou medalhas de estímulo, variar níveis de dificuldade estimulando o jogador a melhorar seu desempenho, e criar histórias a fim de tornar o jogo lúdico mas de forma com que o jogador se identifique com um personagem ou enredo.

Além disso, Zichermann e Cunningham (2012) destacam que o design do jogo 
também é um componente importante. Uma das estruturas mais empregadas é definida como estrutura MDA (mecânica, dinâmica e estética). A mecânica compreende os componentes funcionais do jogo (regras e recompensas que provocam emoções positivas no jogador). As dinâmicas tratam das interações do jogador com os elementos definidos na mecânica do jogo (desejos e motivações que levam a buscar as emoções). Já o componente estética engloba os elementos da mecânica e da dinâmica, como eles interagem e criam as situações do jogos e provocam emoções.

Prensky (2001) aponta 12 fatores que tornam os jogos atrativos: a diversão que gera prazer, a ação de jogar que gera envolvimento, as regras que fornecem a estrutura, as metas que geram a motivação, a interatividade que leva a ação, as etapas que geram caminhos, o feedback que proporciona o aprendizado, a passagem de níveis que traz a recompensa, os desafios que proporcionam adrenalina, a resolução de problemas que desperta a criatividade, a interação que promove a integração dos indivíduos, a história envolvida que gera emoção.

Apesar dos diversos estudos nessa área, não existe até o momento uma classificação consensual dos elementos de jogos que poderiam fornecer para os pesquisadores uma linguagem comum para estudar os efeitos desses atributos na aprendizagem. Bedwell (2012) propõe uma classificação de elementos de jogos que podem levar a resultados positivos quando usados na aprendizagem (Tabela 1).

Tabela 1 - Elementos significativos para a aprendizagem

\begin{tabular}{l|l}
\hline \multicolumn{1}{c|}{ Atributo } & \multicolumn{1}{c}{ Definição } \\
\hline Adaptação & Nível de dificuldade se ajusta ao nível de habilidade do jogador \\
\hline Avaliação & A medida de realização dentro do jogo \\
\hline Desafio & Quantidade ideal de dificuldade \\
\hline Conflito & Interações diretas, indiretas, violentas, ou não violentas \\
\hline Controle & Poder ou a influência sobre os elementos do jogo \\
\hline Fantasia & Ambientes, cenários ou personagens inusitados \\
\hline Interação & Pode ser com o jogo, com outros jogadores e com o grupo. \\
\hline Idioma/comunicação & Regras específicas de comunicação (verbal ou textual) do jogo \\
\hline Localização & Mundo físico ou virtual do jogo \\
\hline Mistério & Provoca a curiosidade, novidades, surpresas, complexidade e ideias \\
\hline Peças ou jogadores & Os objetos ou pessoas que são incluídos no cenário ou na narrativa do jogo \\
\hline Progresso & Como o jogador progride em direção aos objetivos do jogo \\
\hline Surpresa & Elementos aleatórios não conhecidos pelos jogadores \\
\hline Representação & Característica que faz com que o jogo pareça psicologicamente real \\
\hline Regras/ Metas & Regras estabelecidas no jogo para atingir o objetivo \\
\hline Segurança & Liberação de ações e consequências \\
\hline
\end{tabular}

A fim de validar os elementos de jogo identificados pelos autores, procedeu-se com a realização de testes em jogos atualmente populares nas redes sociais e consoles. A seção seguinte apresenta o estudo realizado e as análises obtidas.

\section{Análise de Jogos Populares}

Como etapa importante deste estudo foram realizados testes em uma amostra de jogos com o intuito de confirmar os elementos que tornam os jogos tão atrativos. Selecionouse uma amostra de quatro jogos considerada representativa das plataformas atuais: Candy Crush (redes sociais), Call of Duty: Black Ops II (Xbox 360), Grand Theft Auto IV (computador), e Angry Birds (dispositivos móveis).

A análise realizada levou em consideração os sete principais elementos citados por Zichermann e Cunningham (2012), além dos atributos definidos por Bedwell et al. (2013). O primeiro jogo avaliado foi o Candy Crush. Se trata de um jogo temático 
contendo um tabuleiro composto com doces e cores diferentes, onde é necessário combinar doces da mesma cor até que não haja mais nenhum doce no tabuleiro. Cada vez que todas as peças são removidas do tabuleiro, o jogo avança para a fase seguinte com nível de dificuldade maior. A cada fase que o jogador encerra, ele recebe uma pontuação e uma classificação em relação aos seus amigos no Facebook, podendo compartilhar ou não essa informação. Durante o jogo, o jogador recebe algumas missões especiais chamadas de fases combos, onde o jogador recebe estrelas como recompensas por executar a missão com sucesso.

O segundo jogo avaliado foi o Call of Duty: Black Ops II. O jogo começa em um cenário de guerra onde o personagem é um soldado e precisa derrotar o exército inimigo lutando em várias missões secretas. No decorrer do jogo são mostrados ao jogador os inimigos que ele deve atingir (seus objetivos). Assim que a missão for cumprida, o personagem começa uma nova missão. Além disso, o jogo possui missões especiais que são fornecidas para os jogadores irem escolhendo durante o percurso.

O terceiro jogo avaliado foi o GTA IV, cujo objetivo é controlar um personagem em diferentes ambientes. Este é um jogo onde o personagem comete diversos crimes, como roubar e matar. No decorrer do jogo, quando o personagem completa as missões a ele destinadas, recebe pontos (dinheiro). Ele também pode aumentar a sua quantidade de dinheiro quando rouba dinheiro, ambulância ou táxi para iniciar uma nova missão. No entanto, ao praticar alguns destes crimes o personagem pode chamar a atenção da polícia e terá que fugir para não ser preso e poder continuar seu percurso. $\mathrm{O}$ jogo não possui uma sequência definida em que o jogador deve seguir rigorosamente. No entanto, jogador precisa completar as missões para poder dar continuidade ao enredo, liberando certas áreas e estabelecimentos do jogo. Também há missões que vão surgindo inesperadamente. O jogador pode visualizar seu desempenho através de um mapa.

Por fim, o jogo Angry Birds consiste em uma batalha entre pássaros e porcos verdes. Ao ter seus ovos roubados pelos porcos verdes, os pássaros precisam matar os porcos para poder recuperar os ovos. O jogo tem várias etapas a serem completadas e em cada uma delas existem várias fases onde a dificuldade cresce e a reserva de pássaros disponíveis diminui. A ordem de execução destas etapas pode ser escolhida pelo usuário, sem a necessidade de uma sequência determinada. Em cada fase concluída, o jogador pode receber uma, duas ou três estrelas, dependendo da pontuação que ele totalizou no jogo. O jogador pode analisar seu progresso no jogo através de um painel com as fases cumpridas e com as que ainda não foram executadas.

A relação entre o sucesso dos jogos e os elementos usados no seu desenvolvimento é de extrema importância para que se possa analisar de que forma estes elementos operam nestes jogos e qual o efeito que eles provocam nos jogadores. A Tabela 2 apresenta os elementos presentes em cada um dos quatro jogos analisados.

\section{Materiais e Métodos}

O propósito deste estudo foi avaliar o desempenho de softwares de autoria no desenvolvimento de jogos educacionais simples. Inicialmente foram selecionados quatro softwares de autoria empregados na criação de jogos educacionais. Estes softwares foram escolhidos por serem gratuitos ou por terem versões demo disponíveis. Entre eles está o Visual Class (http://www.class.com.br/), o Jclic (http://clic.xtec.cat/en/jclic/), o Ardora(http://webardora.net/index_ing.htm) e o Hot Potatoes(https://hotpot.uvic.ca/). Para permitir a padronização dos testes optou-se por implementar em cada um deles um conjunto de jogos e atividades incluindo: quebra-cabeças, caça-palavras, associação de colunas, perguntas e respostas e verdadeiro ou falso. Jogos simples e bem conhecidos são mais facilmente compreendidos pelos alunos, favorecendo a concentração no 
conteúdo alvo da aprendizagem. Do ponto de vista do professor, eles são versáteis pois podem ser trabalhados em diversas disciplinas. Além disso, eles permitiram a rápida prototipação nos quatro softwares de autoria.

Tabela 2 - Avaliação dos jogos em termos de suas características

\begin{tabular}{l|c|c|c|c}
\hline \multicolumn{1}{c|}{ Elementos } & $\begin{array}{c}\text { Candy } \\
\text { Crush }\end{array}$ & $\begin{array}{c}\text { Call of Duty: } \\
\text { Black Ops II }\end{array}$ & $\begin{array}{c}\text { GTA } \\
\text { IV }\end{array}$ & $\begin{array}{c}\text { Angry } \\
\text { Birds }\end{array}$ \\
\hline Pontos & $\mathrm{X}$ & - & $\mathrm{X}$ & $\mathrm{X}$ \\
\hline Níveis & $\mathrm{X}$ & $\mathrm{X}$ & $\mathrm{X}$ & $\mathrm{X}$ \\
\hline Ranking de Líderes & $\mathrm{X}$ & - & $\mathrm{X}$ & $\mathrm{X}$ \\
\hline Medalhas/Recompensas & $\mathrm{X}$ & $\mathrm{X}$ & $\mathrm{X}$ & $\mathrm{X}$ \\
\hline Integração & $\mathrm{X}$ & $\mathrm{X}$ & $\mathrm{X}$ & $\mathrm{X}$ \\
\hline Desafios e missões & $\mathrm{X}$ & $\mathrm{X}$ & $\mathrm{X}$ & $\mathrm{X}$ \\
\hline Laços de engajamento & $\mathrm{X}$ & $\mathrm{X}$ & $\mathrm{X}$ & $\mathrm{X}$ \\
\hline Linguagem/Comunicação & $\mathrm{X}$ & $\mathrm{X}$ & $\mathrm{X}$ & $\mathrm{X}$ \\
\hline Avaliação/Progresso & $\mathrm{X}$ & $\mathrm{X}$ & $\mathrm{X}$ & $\mathrm{X}$ \\
\hline Desafio/Conflito/Surpresa & $\mathrm{X}$ & $\mathrm{X}$ & $\mathrm{X}$ & $\mathrm{X}$ \\
\hline Controle/Interação (equipamento) & - & $\mathrm{X}$ & $\mathrm{X}$ & - \\
\hline Localização & $\mathrm{X}$ & $\mathrm{X}$ & $\mathrm{X}$ & $\mathrm{X}$ \\
\hline Fantasia/Mistério & $\mathrm{X}$ & $\mathrm{X}$ & $\mathrm{X}$ & $\mathrm{X}$ \\
\hline Interação Humana (interpessoal), Interação (social). & $\mathrm{X}$ & $\mathrm{X}$ & - & $\mathrm{X}$ \\
\hline Peças ou Jogadores,estímulos sensoriais, segurança. & - & $\mathrm{X}$ & $\mathrm{X}$ & $\mathrm{X}$ \\
\hline Regras e metas & $\mathrm{X}$ & $\mathrm{X}$ & $\mathrm{X}$ & $\mathrm{X}$ \\
\hline \multicolumn{1}{|c|}{ O tema central dos jogos foramn conceitros }
\end{tabular}

O tema central dos jogos foram conceitos de Redes de Computadores estudados em cursos de graduação em Computação. Cada nível do jogo esteve relacionado a um tópico deste domínio, sendo que o nível de dificuldade aumentava gradualmente a cada nível. Os jogos foram organizados em telas, sendo a tela inicial de boas vindas e login. Em cada tela são apresentadas informações sobre o jogo (pontuação e prêmios), além de botões de ajuda, progresso e finalização do jogo. As Figuras 1 e 2 apresentam respectivamente os protótipos da tela inicial, jogo principal, jogo surpresa e progresso.
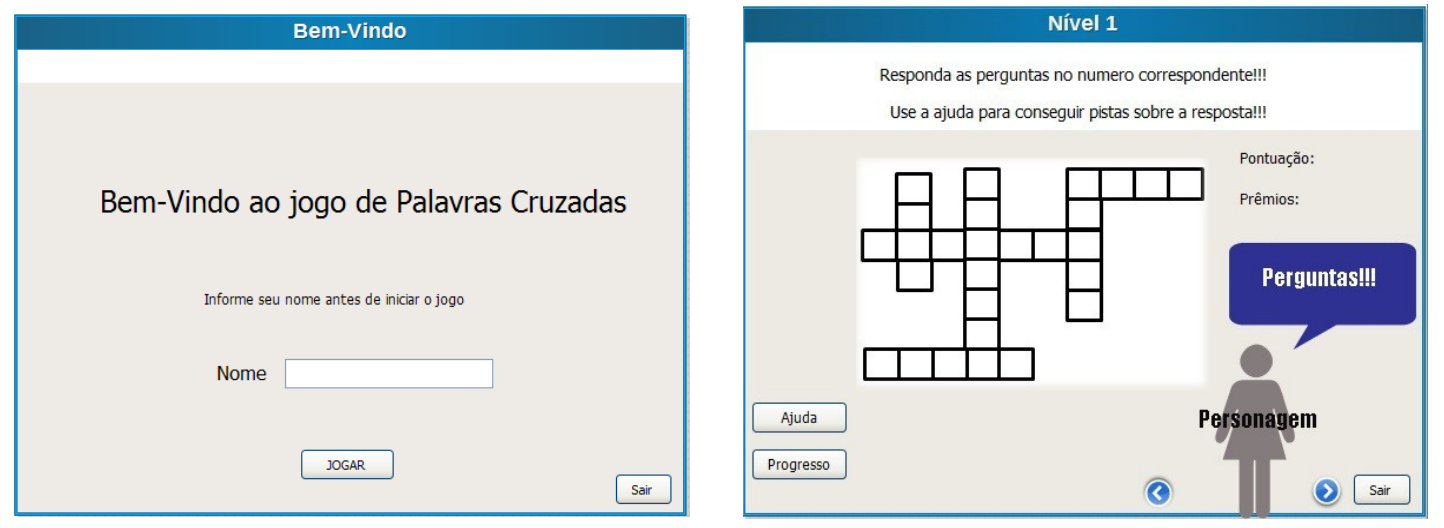

Figura 1 - Tela inicial e nível 1 do jogo proposto.

Por meio do botão progresso o jogador visualiza seu avanço no jogo: quantidade de níveis concluídos, o que falta para finalizar o jogo, a pontuação total, a quantidade de prêmios obtidos e a classificação dos jogadores de acordo com os pontos obtidos.

Quando o jogador inicia o primeiro jogo de palavras-cruzadas, o jogo oferece diversas informações sobre como prosseguir no jogo. O personagem mostra a primeira pergunta e o jogador deve responder. Se ele não souber a resposta, ele pode seguir para a próxima pergunta ou pedir ajuda. Como o número de ajudas é limitado, a cada ajuda 
adicional devem ser retirados 10 pontos. Cada acerto equivale a 10 pontos adicionais. Caso o jogador consiga concluir uma fase sem solicitar ajuda, ele ganha como prêmio uma estrela (50 pontos). Além disso, toda vez que o jogador acertar uma resposta, o sistema emite um sinal sonoro. A cada 150 pontos, o jogador recebe uma missão. É apresentado na tela um jogo surpresa (do tipo caça-palavras) para o qual o jogador precisará encontrar algumas palavras em um tempo determinado. Caso o jogador consiga finalizar a missão antes de acabar o tempo, ele recebe como prêmio três estrelas.
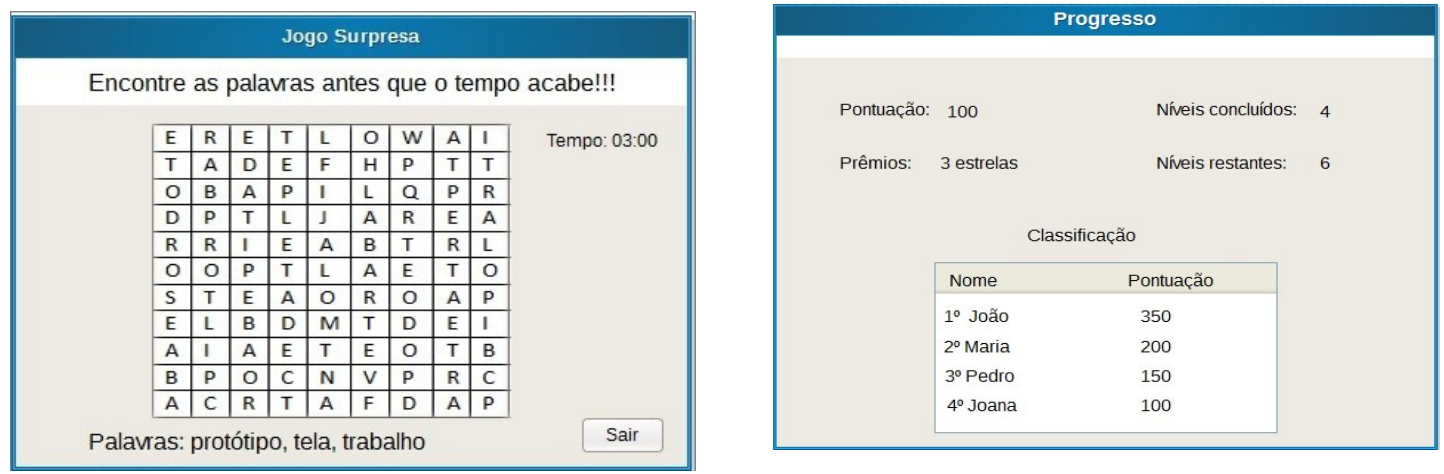

Figura 2 - Telas do jogo proposto: etapa surpresa e progresso

Este projeto foi elaborado a fim de contemplar os elementos encontrados em jogos que engajam o usuário, destacados por Zichermann e Cunningham (2012) e por Bedwell et al. (2012). A Tabela 3 apresenta os critérios utilizados nos testes.

Tabela 3 - Representação dos critérios no jogo

\begin{tabular}{|c|c|c|}
\hline & Elementos & Representação no Jogo \\
\hline $\mathrm{C} 1$ & Pontos & 10 pontos por resposta correta. \\
\hline $\mathrm{C} 2$ & Níveis & Cada nova palavra cruzada o nível de dificuldade aumenta. \\
\hline $\mathrm{C} 3$ & Líderes & Na opção progresso haverá uma lista de classificação por pontos. \\
\hline $\mathrm{C} 4$ & $\begin{array}{l}\text { Medalhas/ } \\
\text { Recompensas }\end{array}$ & $\begin{array}{l}\text { Serão usadas estrelas como recompensas para os usuários que } \\
\text { conseguirem passar uma fase sem ajuda e no tempo. }\end{array}$ \\
\hline $\mathrm{C} 5$ & Integração & $\begin{array}{l}\text { Os níveis de dificuldade e o desejo de concluir todos os níveis e } \\
\text { receber pontuação maior tornam o jogo atraente. }\end{array}$ \\
\hline C6 & Desafios e missões & $\begin{array}{l}\text { Quando o jogador somar } 150 \text { pontos é lançado um desafio para } \\
\text { ele. }\end{array}$ \\
\hline $\mathrm{C} 7$ & Laços de engajamento & A classificação por pontos torna o jogo competitivo \\
\hline $\mathrm{C} 8$ & $\begin{array}{l}\text { Linguagem/ } \\
\text { Comunicação }\end{array}$ & $\begin{array}{l}\text { Os jogadores utilizaram o mouse do computador para realizar as } \\
\text { ações desejadas e o teclado para digitar a resposta. }\end{array}$ \\
\hline C9 & Avaliação/Progresso & O progresso poderá ser analisado (níveis completos/incompletos) \\
\hline $\mathrm{C} 10$ & $\begin{array}{l}\text { Desafio/Conflito/ } \\
\text { Surpresa }\end{array}$ & O desafio no jogo será a dificuldade que aumenta gradativamente \\
\hline $\mathrm{C} 11$ & $\begin{array}{l}\text { Controle/Interação } \\
\text { (equipamento) }\end{array}$ & $\begin{array}{l}\text { Toda vez que o jogador digitar a resposta correta o sistema emite } \\
\text { um som. }\end{array}$ \\
\hline $\mathrm{C} 12$ & Localização & Uso de um cenário de fundo referente às perguntas realizadas. \\
\hline $\mathrm{C} 13$ & Fantasia/Mistério & Uso do mesmo cenário de fundo para envolver o jogador no jogo. \\
\hline $\mathrm{C} 14$ & $\begin{array}{l}\text { Interação Humana } \\
\text { (interpessoal), Interação } \\
\text { (social). }\end{array}$ & $\begin{array}{l}\text { Através de classificação por pontos será possível verificar sua } \\
\text { pontuação em relação a outros jogadores. }\end{array}$ \\
\hline $\mathrm{C} 15$ & $\begin{array}{l}\text { Peças ou Jogadores, } \\
\text { Representação, estímulos } \\
\text { sensoriais, segurança. }\end{array}$ & $\begin{array}{l}\text { Um personagem que apresenta as perguntas estará incluído no } \\
\text { cenário do jogo. }\end{array}$ \\
\hline $\mathrm{C} 16$ & Regras e metas & As regras do jogo são apresentadas para o jogador no início. \\
\hline $\mathrm{C} 10$ & $\begin{array}{l}\text { Desafio/Conflito/ } \\
\text { Surpresa }\end{array}$ & $\begin{array}{l}\text { O desafio no jogo será a dificuldade que aumenta gradativamente e } \\
\text { o jogo de caça-palavras que aparece repentinamente. }\end{array}$ \\
\hline
\end{tabular}


O Método Analítico Hierárquico (MAH) foi utilizado para identificar qual o software de autoria mais apropriado para o uso em sala de aula. O MAH é uma ferramenta multicritério utilizado na tomada de decisão (BARAÇAS e MACHADO, 2006). A análise dos softwares de autoria foi feita por meio do desenvolvimento de jogos educacionais usando as ferramentas disponibilizadas em cada software. Em todos eles foi implementado o mesmo jogo para permitir a comparação. O jogo proposto foi direcionado a estudantes universitários da disciplina de redes de computadores.

\section{Resultados Obtidos}

A análise nos softwares de autoria foi realizada implementando o jogo proposto que contempla todos os critérios apresentados na Tabela 4 e verificando se o software possibilita ou não tal implementação. Os testes foram feitos em cada um dos softwares e depois foram elaboradas as matrizes de avaliação para cada critério.

Apesar de o MAH possibilitar a definição de diferentes pesos para cada critério, neste caso, todos os critérios receberam o mesmo peso (9). Os pesos foram definidos com o mesmo valor pois considerou-se que todos os critérios possuíam igual importância. Além disso, de acordo com o tipo de jogo, a importância dos critérios podem variar. Em um jogo de estratégia os critérios mais importantes podem ser diferentes dos que os usados em um jogo de aventura. No final das comparações, os pesos foram multiplicados pelas médias obtidas, onde o maior resultado indicou o melhor software de autoria.

A análise dos softwares foi feita inicialmente cruzando as funcionalidades e características dos softwares com os critérios de avaliação (Tabela 4). Em cada célula, onde ocorre o cruzamento é atribuída a palavra "NÃO" quando o software não atendeu ao respectivo critério, "SIM" quando o software atendeu o critério e "PARCIAL" quando o software atendeu parcialmente ao critério.

Tabela 4 - Tabela geral do cruzamento entre softwares e critérios

\begin{tabular}{|c|c|c|c|c|}
\hline Critérios & Visual Class & JClic & Hot Potatoes & Ardora \\
\hline $\mathrm{C} 1$ & SIM & PARCIAL & $\mathrm{NÂO}$ & $\mathrm{NÂO}$ \\
\hline $\mathrm{C} 2$ & SIM & SIM & SIM & NÃO \\
\hline $\mathrm{C} 3$ & PARCIAL & $\mathrm{NA \tilde {O }}$ & $\mathrm{NÃO}$ & NÂO \\
\hline $\mathrm{C} 4$ & NÃO & NÃO & NÃO & NÂO \\
\hline $\mathrm{C} 5$ & PARCIAL & PARCIAL & PARCIAL & $\mathrm{NÃO}$ \\
\hline C6 & $\mathrm{NÃO}$ & $\mathrm{NÃO}$ & $\mathrm{NÃO}$ & $\mathrm{NÃO}$ \\
\hline $\mathrm{C} 7$ & PARCIAL & $\mathrm{NÃO}$ & $\mathrm{NÃO}$ & $\mathrm{NÃO}$ \\
\hline $\mathrm{C} 8$ & SIM & SIM & SIM & SIM \\
\hline C9 & NÃO & $\mathrm{NÃO}$ & NÃO & $\mathrm{NÃO}$ \\
\hline $\mathrm{C} 10$ & PARCIAL & PARCIAL & PARCIAL & NÂO \\
\hline $\mathrm{C} 11$ & NÃO & SIM & NÂO & NÂO \\
\hline $\mathrm{C} 12$ & SIM & SIM & SIM & $\overline{\mathrm{NÂO}}$ \\
\hline$\overline{\mathrm{C} 13}$ & SIM & SIM & SIM & $\overline{\mathrm{NÂO}}$ \\
\hline $\mathrm{C} 14$ & PARCIAL & $\mathrm{NÃO}$ & $\mathrm{NÃO}$ & $\mathrm{NÃO}$ \\
\hline $\mathrm{C} 15$ & SIM & $\mathrm{NÃO}$ & NÃO & $\mathrm{NÃO}$ \\
\hline $\mathrm{C} 16$ & SIM & SIM & SIM & SIM \\
\hline
\end{tabular}

$\mathrm{Na}$ segunda etapa foi realizada a comparação através de matrizes. Essa comparação foi realizada comparando, em uma matriz, cada software de autoria por todos. A matriz de avaliação foi feita para todos os critérios de análise. Na Tabela, as linhas e colunas demonstram o cruzamento de cada um dos softwares em relação a um critério. As comparações foram analisadas observando o software da linha em relação ao software da coluna. Quando o software foi comparado com ele mesmo, foi atribuído o valor 1, que é relativamente o peso mais baixo no MAH. Quando o software da linha atendeu ao critério que está sendo analisado e o software da coluna não atendeu foi 
atribuído o peso 9, que demonstra importância absoluta, relativamente o grau mais alto no MAH. E quando o software da linha atendeu parcialmente o critério e o software da coluna não atendeu ao critério foi atribuído o valor 5 , que está entre o peso mais baixo e o mais alto no MAH. De maneira oposta, quando o software que está na linha não atendeu o critério e o software da coluna atendeu foi atribuído o peso proporcionalmente inverso, 1/9 ou 1/5 no caso de ter atendido parcialmente o critério. Quando ambos os softwares atenderam o critério ou ambos os softwares não atenderam ou ainda se ambos atenderam de forma parcial o critério foi atribuído valor 1.

A última linha de cada matriz representa a soma de cada coluna, que foi utilizado para calcular a média, que fica na última coluna da matriz. A média representa o resultado da avaliação de cada software com relação aos demais para cada critério. Para calcular a média foi utilizado o seguinte cálculo: ((valor da linha $1 /$ soma coluna 1) + (valor da linha $\mathrm{N}$ / soma coluna $\mathrm{N}$ )) / $\mathrm{N}$, para $\mathrm{N}$ de 1 até o número de elementos.

Por fim, foi criada uma matriz das médias encontradas para cada um dos critérios (Tabela 4). Cada célula representa a média obtida pelo software para aquele critério de avaliação. A Tabela 5 apresenta ainda na última linha da matriz a pontuação total de cada um dos softwares. O resultado final apresenta a maior pontuação na soma de todos os critérios para o software Visual Class com a pontuação total de 4,98. O JClic ficou em segundo com uma pontuação de 2,996, em terceiro o Hot Potatoes com 2,184 e em última colocação o software Ardora com uma pontuação total de 0,826 .

A utilização do MAH para avaliação dos softwares permitiu identificar com clareza os critérios atendidos em cada software. Além disso, a construção das matrizes de avaliação para cada critério permitiu visualizar em quais pontos cada software se destaca em relação as demais.

Tabela 5 - Matriz da Média dos Critérios

\begin{tabular}{l|c|c|c|c}
\hline \multicolumn{1}{c|}{ Critérios } & JClic & Hot Potatoes & Visual Class & Ardora \\
\hline C1 & 0,201 & 0,056 & 0,685 & 0,056 \\
\hline C2 & 0,321 & 0,321 & 0,321 & 0,035 \\
\hline C3 & 0,125 & 0,125 & 0,625 & 0,125 \\
\hline C5 & 0,312 & 0,312 & 0,312 & 0,062 \\
\hline C7 & 0,125 & 0,125 & 0,625 & 0,125 \\
\hline C10 & 0,312 & 0,312 & 0,312 & 0,062 \\
\hline C11 & 0,750 & 0,083 & 0,083 & 0,083 \\
\hline C12 & 0,321 & 0,321 & 0,321 & 0,035 \\
\hline C13 & 0,321 & 0,321 & 0,321 & 0,035 \\
\hline C14 & 0,125 & 0,125 & 0,625 & 0,125 \\
\hline C15 & 0,083 & 0,083 & 0,750 & 0,083 \\
\hline Total & 2,996 & 2,184 & 4,98 & 0,826 \\
\hline
\end{tabular}

A Tabela 6 apresenta a classificação obtida com base na pontuação total. A primeira coluna apresenta a posição do software em relação aos demais, considerando como 1 a melhor avaliação. As próximas colunas apresentam o nome de cada software, a pontuação recebida, a quantidade de critérios atendidos e a quantidade de critérios atendidos parcialmente pelos softwares.

\begin{tabular}{c|c|c|c|c}
\multicolumn{7}{c}{ Tabela 6- Ranking dos softwares de autoria } \\
\hline Ranking & Software & Pontuação Total & Critérios Atendidos & Parcialmente Atendidos \\
\hline 1 & Visual Class & 4,98 & 7 & 5 \\
\hline 2 & JClic & 2,996 & 6 & 3 \\
\hline 3 & Hot Potatoes & 2,184 & 5 & 2 \\
\hline 4 & Ardora & 0,826 & 2 & 0 \\
\hline
\end{tabular}

Analisando o ranking e todas as análises realizadas, nenhum dos softwares está 
adequado totalmente aos critérios propostos. Pode-se notar claramente a ausência de critérios considerados fundamentais no desenvolvimento de jogos educacionais.

O software que demonstrou melhores resultados e, portanto teve o maior valor foi o Visual Class. O Visual Class atendeu 7 critérios de forma completa e a 5 de forma parcial, permitindo a criação de um jogo educativo razoável considerando os conceitos estudados sobre jogos educativos. O software poderia oferecer ferramentas que possibilitassem a criação de uma lista de classificação por pontos automática feita pelo software na qual contemplaria os critérios $\mathrm{C} 3, \mathrm{C} 5$ e $\mathrm{C} 7$ que foram atendidos parcialmente e que estão vinculados ao mesmo objetivo. Além disso, o software poderia oferecer ao autor do jogo uma configuração que possibilite oferecer uma recompensa ao jogador ao realizar determinada pontuação ou atividade, atendendo assim ao critério $\mathrm{C} 4$ considerado essencial para gerar um sentimento de satisfação no jogador. Outra característica que tornaria o software mais apropriado e eficaz em salas de aula seria permitir a inclusão de algum tipo de desafio no decorrer do jogo para evitar que ele se torne monótono e chato. Esta característica atenderia aos critérios $\mathrm{C} 6$ e $\mathrm{C} 10$ e faria com que o software se tornasse um exemplo entre os softwares de autoria. O critério C11 não foi atendido pelo software, mas não causaria tanto impacto a ausência dele nos jogos desenvolvidos, como acontece com os demais critérios citados.

O JClic foi o único software que, entre os testados atendeu ao critério C11, mas em relação aos outros critérios ele foi avaliado de forma análoga aos demais ou inferior. Ele atendeu de forma total a 6 critérios e de forma parcial a outros 3 critérios. Ele não atendeu a 7 dos 16 critérios, ficando desta maneira como o segundo melhor software. $\mathrm{O}$ Hot Potatoes não teve nenhum destaque, já que na avaliação dos critérios ele teve uma avaliação inferior ou igual aos softwares da primeira e segunda posição. Ele atendeu de forma completa a 5 critérios, como visto na Tabela 4, de forma parcial a 2 dos critérios avaliados, e 9 dos critérios não foram atendidos pelo Hot Potatoes. O software Ardora foi o último colocado com uma pontuação bem inferior ao do Hot Potatoes. Ele só atendeu a 2 dos 16 critérios definidos e os demais critérios não foram atendidos pelo software nem de forma parcial. Essa foi a pior avaliação entre os softwares sem nenhum ponto forte para destacar. Na avaliação ainda pode-se perceber que os critérios C4 e C6 foram os únicos critérios que não foram atendidos pelo software. Ao contrário, os critérios C8 e C16 foram os únicos atendidos por todos os softwares.

No geral todos os softwares permitiram o desenvolvimento de jogos educacionais, o Visual Class e O JClic de forma mais completa, atendendo a maioria dos critérios de forma completa ou parcial e de forma bem simples sem a inclusão da maioria dos critérios, o software Hot Potatoes e o Ardora. Todos permitiram o desenvolvimento dos jogos, porém essa variação entre os critérios atendidos e não atendidos podem ter resultados positivos ou negativos dentro das salas de aula.

\section{Conclusão}

O desenvolvimento de tecnologias educacionais baseadas em jogos constitui um desafio tanto do ponto de vista didático quanto computacional. Os jogos digitais implementam recursos e elementos que funcionam para engajar um usuário em um jogo longo, com muitos níveis e desafios. Diversos artigos referenciados neste artigo trataram de identificar tais elementos e adaptá-los para o desenvolvimento de softwares educacionais com características de jogos (gamificados). Observações têm apontado que ao menos o engajamento e a motivação dos alunos são aumentados. Considerando que esses fatores são significativos para impulsionar uma aprendizagem, incorporá-los aos ambientes educacionais já pode ser visto como uma melhoria.

É sabido que desenvolver um jogo digital exige grande investimento (recursos 
humanos, financeiros e computacionais). Desenvolver um produto sofisticado unicamente para o ensino é praticamente inviável em nossa realidade. A solução abordada neste artigo propõe desenvolver jogos simples utilizando ferramentas de autoria de licença livre em uso educacional.

Outro fator que deve ser levado em conta é que um dos objetivos da área de Informática na Educação é desenvolver ferramentas de software que proporcionem autonomia aos educadores para produzir e gerenciar seus próprios materiais didáticos. Os softwares de autoria são um exemplo de ferramentas facilitadoras desse processo. Além de serem aplicáveis em diversas disciplinas, as ferramentas de autoria possuem linguagens de programação simplificadas, que um professor pode aprender rapidamente.

$\mathrm{O}$ uso de recursos que habilitem o professor a transpor seu processo didático para a forma de jogos é uma forma prática e facilitada de incorporar resultados de pesquisa para melhorar as suas práticas no dia a dia. Neste artigo investigamos a aplicação das ferramentas de autoria no desenvolvimento de jogos educacionais simples. Algumas ferramentas foram testadas e avaliadas segundo critérios próprios da área de jogos digitais aplicados ao ensino. Os resultados obtidos a partir dos testes dos softwares permitem inferir que a ferramenta Visual Class é atualmente a mais completa.

\section{Referências Bibliográficas}

AVELLAR, C. et al. Modelo de Análise de Gamificação Aplicado a Redes Sociais Gamificadas. In: Simpósio Brasileiro de Games e Entretenimento Digital, 6., 2012, Brasília. Proceedings. Brasília: Sbgames, 2012. p. 189 - 196.

BARAÇAS, F. J. L.; MACHADO, J. P. A. A Análise Multicritério na Tomada de Decisão - o Método Analítico Hierárquico de T. L. Saaty. 2006. Instituto Politécnico de Coimbra, 2006. BEDWELL, W. L. et al. Toward a Taxonomy Linking Game Attributes to Learning: An Empirical Study. Simulation \& Gaming, Orlando, v. 43, p. 729-760. 14 mai. 2012.

DOMÍNGUEZ, A. et al. Gamifying learning experiences: Practical implications and outcomes. Computers \& Education, Madrid, v. 63, p. 380-392. Abr. 2013.

FALKEMBACH, G. A. M. Ferramentas de autoria. Universidade Federal do Rio Grande do Sul, Centro Interdisciplinar de Novas Tecnologias na Educação. 2007.

FARDO, M.L. A gamificação aplicada em ambientes de aprendizagem. Renote, Porto Alegre, v. 11, n. 1, Jul. 2013.

GEE, J. P. G. Good videogames and Good Learning. PHI KAPPA PHI FORUM/VOL. 85, NO.2, 2005, p. 33-37.

KAPP, K. The Gamification of learning and instruction game-based methods and strategies for trainning and education. San Francisco: Pfeiffer. 2012.

McGONIGAL, J. A realidade em jogo: Por que os games nos tornam melhores e como eles podem mudar o mundo. Rio de Janeiro: Ed. Best Seller, 2012.

NAVARRO, G. Gamificação: a transformação do conceito de termo jogo no contexto da pósmodernidade. 2013. 26 f. TCC (Especialização) - Universidade de São Paulo, Curso de Especialização em Mídia, Informação e Cultura, 2013.

POSSANI, M. F.; SANTOS, E. R. V.; LOPES, A. M. Z. Sistemas de gestão web e o uso da gamificação para motivar e fidelizar usuários.In: ENCONTRO CIENTÍFICO DO GEPRO, 3., 2013, Jaú. Anais. São Paulo: FATEC-JAHU, 2013.

PRENSKY, M. Digital game-based learning. New York: McGraw-Hill, 2001.

PRENSKY, M. The Motivation of Gameplay or the REAL 21st century learning revolution. On The Horizon, Volume 10 No 1., 2002.

QUADROS, G.B.F. Gamificando os processos de ensino na rede. In: CONGRESSO NAC. UNIVERSIDADE, EAD E SOFTWARE LIVRE, 3., Anais. Belo Horizonte: UFMG, 2013.

ZICHERMANN, G; CUNNINGHAN, C. Gamification by Design: Implementing Game Mechanics in Web and Mobile Apps. Sebastopol: O'reilly Media, 2011. 208 p. 